\title{
Characteristics and Outcomes of Extreme Elderly Patients With Hepatocellular Carcinoma in South Korea
}

\author{
JI HO SEO, DONG HYUN KIM, EUNAE CHO, CHUNG HWAN JUN, SEON YOUNG PARK, \\ SUNG BUM CHO, CHANG HWAN PARK, HYUN SOO KIM, SUNG KYU CHOI and JONG SUN REW \\ Division of Gastroenterology, Department of Internal Medicine, \\ Chonnam National University Hospital and Medical School, Gwangju, Republic of Korea
}

\begin{abstract}
Background/Aim: The number of elderly patients diagnosed with hepatocellular carcinoma (HCC) has been increasing. But there is no proper management based on age stratification in elderly patients. Therefore, we evaluated the clinical characteristics and outcomes of elderly HCC patients more than 75 years old in South Korea. Patients and Methods: Five hundred and fifty elderly patients with HCC were enrolled and divided into the oldest-old (age $\geq 85$ years), middle-old (age between 80 and 85 years), and young-old groups (age between 75 and 80 years). Results: Fifty-one, 153, and 346 patients were included in the oldestold (mean age: 87 years), middle-old (mean age: 82 years), and young-old groups (mean age: 77 years), respectively. There was a significantly lower rate of alcohol-related and hepatitis $B$ virus-related diseases in the oldest-old group than in the other groups, whereas there was no significant difference in other characteristics. With increasing age, conservative treatment was predominantly performed. Transarterial chemoembolization was the main modality of active treatment in all groups. In multivariate analysis, the performance score, model for end-stage liver disease score, modified Union for International Cancer Control staging, Barcelona Clinic Liver Cancer staging, presence of portal vein tumor thrombosis, ruptured $\mathrm{HCC}$, and active treatment were risk factors of overall survival. Conclusion: When the therapeutic approach is used in elderly patients with HCC, the patient's performance status, liver function, and stage of
\end{abstract}

This article is freely accessible online.

Correspondence to: Dr. Chung Hwan Jun, Department of Internal Medicine, Chonnam National University Hospital and Medical School, 42 Jaebong-ro, Donggu, Gwangju 61469, Republic of Korea. Tel: +82 622206296, Fax: +82 622208578, e-mail: estevanj@naver.com

Key Words: Hepatocellular carcinoma, extreme elderly, efficacy, safety. cancer should be considered, and its use should not be restricted to those of advanced age.

Hepatocellular carcinoma (HCC) is the fifth most common cancer worldwide and the second leading cause of cancerrelated death $(1,2)$. The risk of developing HCC is wellknown to be age-dependent $(3,4)$. Since an increase in the longevity of the general population is expected, there will be an increase in the number of elderly or even extreme elderly patients diagnosed with HCC.

The concept of "elderly" has become more difficult to define. The definition of elderly differs mostly because the life expectancy varies in different geographical areas (5). Most developed countries have accepted the chronological age of 65 years as the definition of an "elderly" person (6). However, many clinical studies about HCC define elderly patients as those aged 70 years or older (7-13). In South Korea, the average life expectancy is among the longest in the world. According to a report by Statistics Korea in 2015, the average life expectancy reached about 82.2 years $(79.0$ years for men and 85.6 years for women) (14). Moreover, the number of elderly patients with HCC was expected to increase gradually because of the following epidemiological reasons: i) The increasing incidence of liver cirrhosis is not associated with viral hepatitis or alcoholic steatohepatitis, which requires more time to develop into HCC (15); ii) antiviral agents have an effect on viral hepatitis and delay the natural course of the disease (16); and iii) hepatitis $\mathrm{C}$ due to infection generally occurs in adulthood.

Clinicians have difficulty in managing elderly patients with HCC because they have more comorbidities and are diagnosed as having advanced stage HCC compared to younger patients. In recent literature, there are no significant differences between elderly and younger patients' clinical outcomes after management of $\operatorname{HCC}(7,8,10-12,17-19)$. Because previous large cohort studies showed that patients diagnosed as having HCC were aged between 70 and 75 years (7-13), there is an increasing need for tailored management based on age stratification in extreme elderly 
patients who have life expectancies less than 5 years. Therefore, it is important to evaluate the therapeutic safety in and long-term clinical outcomes of extreme elderly patients (age $\geq 75$ years) with HCC.

In the present study, we compared the clinical characteristics and outcomes, including overall survival (OS), and treatment efficacy and safety, of elderly patients aged more than 75 years in South Korea.

\section{Materials and Methods}

Ethics statement. The study protocol was approved by the institutional review board of Chonnam National University Hospital (approval number: CNUH-2018-107). The need for informed consent requirement was waived because the patient data were de-identified.

Study patients. We retrospectively analyzed 1,286 patients (age $\geq 75$ years) who were diagnosed as having HCC in Chonnam National University Hospital of Gwangju, South Korea from January 2010 to December 2016. Seven hundred sixteen patients were excluded because of the following reasons: 1) the presence of metastatic carcinoma; 2) presence of cholangiocarcinoma; 3 ) age $<75$ years at the time of diagnosis; 4) diagnosis of HCC before 2010; and 5) the initial treatment was performed in other institution(s). The enrolled patients were divided into 3 groups according to other published studies: age $\geq 85$ years (oldest-old group), age between 80 and 85 years (middle-old group), and age between 75 and 80 years (youngold group) $(20,21)$. All patients were followed until the occurrence of death, loss of follow-up, or end of follow-up (December 31, 2017). Information regarding death was collected by reviewing hospital medical records and entered into the Korean Statistical Information Service (KOSIS; http://kosis.kr).

The diagnosis of HCC was made based on the guidelines proposed by the Korea Liver Cancer Study Group (22).

Data collection and analysis. Data were collected to evaluate patients' clinical characteristics. Data recorded for each patient included age, sex, body mass index (BMI), comorbidities, the presence of the hepatitis B surface antigen (HBsAg), presence of the hepatitis $\mathrm{C}$ virus (HCV) antibody, presence of cirrhosis, alphafetoprotein (AFP) values, protein induced by vitamin $\mathrm{K}$ absence-II (PIVKA-II) values, presence of HCC rupture, size and number of tumors, presence of portal vein tumor thrombosis (PVTT), performance status according to the Eastern Cooperative Oncology Group, initial therapy, and OS. Levels of AFP and PIVKA-II were measured at the time of the diagnosis of $\mathrm{HCC}$ and divided into two categories: $\leq 200 \mathrm{IU} / \mathrm{ml}$ and $>200 \mathrm{IU} / \mathrm{ml}$; and $\leq 40 \mathrm{mAU} / \mathrm{ml}$ and $>40 \mathrm{mAU} / \mathrm{ml}$, respectively. The Child-Turcotte-Pugh (CTP) score and Model for End-Stage Liver Disease (MELD) score were used to evaluate liver function. The stage of $\mathrm{HCC}$ was assessed using the modified Union for International Cancer Control (mUICC) staging system and the Barcelona Clinic Liver Cancer (BCLC) staging system. If the patient was untreated, the initial treatment modality was regarded as conservative therapy. Treatment-related morbidity was defined as any complication within 30 days of treatment, and treatment-related mortality was defined as death from a complication within 30 days of treatment. Infection, which is a treatment-related complication, was defined as a positive blood/ascites/urine culture and concomitant patient symptom. Disease-free survival was defined as the interval during and after treatment in which a patient remained alive and the disease did not progress. Survival, including cause of death, was investigated by examining the final medical record and/or KOSIS. A survival census was performed on December 31, 2017.

Statistical analysis. Continuous data are expressed as a mean \pm standard deviation, and discrete variables as absolute and relative frequencies. One-way analysis of variance was used to determine whether there were any significant differences between the means of three independent groups. The chi-square test used $2 \times 2$ or $2 \times 3$ contingency tables for categorical data; the Fisher's exact test was used for cases with few expected frequencies $(<5)$. Survival analysis was calculated from the time of cancer diagnosis to death with values censored at the date of the last follow-up, and these data were expressed as median and 95\% confidence interval (CI). Survival analysis was performed using the Kaplan-Meier method and compared by the log-rank test. To assess the potential prognostic factors, univariate and multivariate analyses were performed using the Cox proportional hazard model. Variables associated with survival in the univariate analysis $(p \leq 0.10)$ were entered into the Cox multivariate stepwise regression model to identify independent prognostic factors. The adjusted relative risk (hazard ratio) and 95\% CI were calculated for each independent predictive factor. A two-tailed $p$-value $<0.05$ was considered statistically significant. All statistical analyses were performed using the SPSS 20.0 statistical package (SPSS Inc., Chicago, IL, USA).

\section{Results}

Figure 1 outlines the patient flow through the study. Of 550 enrolled patients, $51(9.3 \%)$ were aged more than 85 years, $153(27.8 \%)$ were aged between 80 and 85 years, and 346 $(62.9 \%)$ were aged between 75 and 80 years.

Patients' baseline characteristics. Patients' demographic and clinical characteristics are summarized in Table I. There were 51 patients in the oldest-old group (mean age $=87.6$ years), 153 in the middle-old group (mean age $=81.9$ years), and 346 in the young-old group (mean age $=77.1$ years). The percentage of female patients was increased with age, but there was no significant difference between the groups. The etiology of liver disease showed some differences between the groups. Alcohol-related and hepatitis B virus (HBV)related $\mathrm{HCC}$, as determined by $\mathrm{HBsAg}$ positivity, was significantly decreased with age. Yet, there was no significant difference in the percentage of HCV-related HCC between the groups. There was a significant difference in the percentage of other etiologies between the groups. In addition, there was no significant difference in the percentage of diabetes mellitus (DM) and resolved $\mathrm{HBV}$ infection between the groups, as determined by HBsAg negativity and hepatitis $\mathrm{B}$ core antibody positivity with or without anti-HBs antibodies. However, compared to the other etiologies, obesity was significantly different between the groups. There was no significant difference between the groups with regard to BMI, underlying comorbid diseases, 


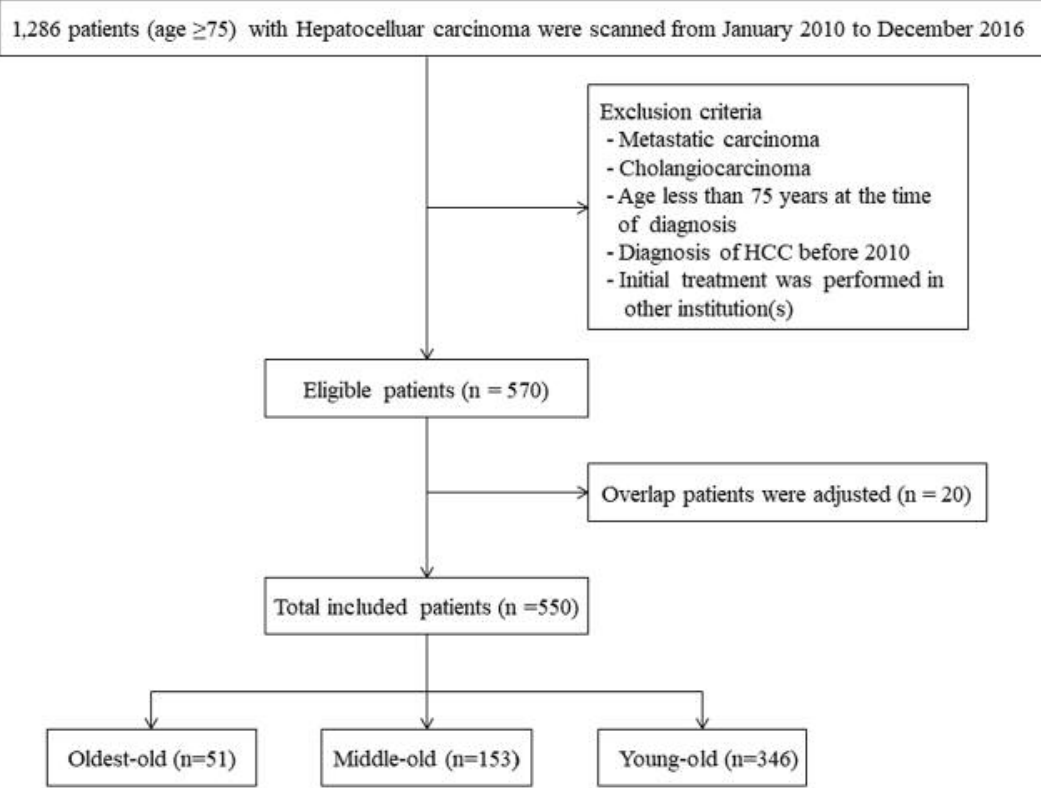

Figure 1. Flow chart of enrolled patients.

the presence of cirrhosis, liver function, presence of PVTT, rupture of $\mathrm{HCC}$, and $\mathrm{HCC}$ stage. Active treatment had a statistically negative correlation with increasing age (oldestold group: $35.3 \%$ versus middle-old group: $53.6 \%$ vs. youngold group: $65.3 \%, p<0.001)$.

Comparison of treatment modalities. Table II shows the treatment modalities used in all 3 groups. Overall, 59.3\% of patients underwent active treatment regardless of age. With increasing age, conservative treatment was predominant (oldestold group: $62.7 \% \mathrm{vs}$. middle-old group: $40.5 \% \mathrm{vs}$. young-old group: $29.2 \%, p<0.001)$. Transarterial chemoembolization (TACE) was the main modality of treatment in all age groups, and it was applied at significantly different rates between the groups (oldest-old group: $21.6 \% \mathrm{vs}$. middle-old group: $34.6 \%$ vs. young-old group: $41.6 \%, p=0.014)$. The percentage of patients receiving, surgical resection, radiofrequency ablation (RFA), sorafenib, and radiotherapy was not significantly different between the groups (Table II).

Characteristics of patients who underwent active treatment. Table III shows the characteristics of patients who underwent active treatment in each age group. There was no significant difference in baseline liver function and HCC stage in the active treatment groups according to age. The consecutive second treatment (defined as switching the modality of treatment) was not significantly different between the groups. The treatment-related adverse events were not significantly different between the groups. The most common adverse event was post-TACE syndrome. Diseasefree survival was not significantly different between the groups. The duration of hospital stay, need for intensive-care unit (ICU) care, and occurrence of infection were not significantly different between the groups. A serious adverse event related to treatment was reported in only 1 case in the middle-age group (Table IV).

Comparison of overall survival between the groups. The mean durations of OS of patients receiving conservative/active treatment were $6.5 / 38.5$ months in the oldest-old group, 11.8/41.5 months in the middle-old group, and 14.8/45.8 months in the young-old group ( $p=0.430$ ) (Table III). There was a significant difference in OS depending on the active treatment used in all groups (Figures 2 and $3 \mathrm{~A}-\mathrm{C}$ ).

A subgroup analysis was performed to exclude the possible effect of the tumor stage or active treatment on OS. OS between the active treatment group and conservative group was compared according to the mUICC stage and BCLC stage (Table V). To perform the subgroup analysis, the 3 groups were divided into 2 groups using different cutoff values for age: extreme elderly group ( $n=51, \geq 85$ years) and non-extreme elderly group ( $n=499$, aged between 75 and 85 years). There were significant differences in OS between the activetreatment group and conservative group based on mUICC stages II and III, but there was no significant difference between the groups for mUICC stages IV-A and IV-B. Similarly, there was a significant difference in the OS between the active treatment group and conservative group based on 
Table I. Demographics and clinical characteristics of enrolled patients.

\begin{tabular}{|c|c|c|c|c|}
\hline Variable & $\begin{array}{l}\text { Oldest-old } \\
(\mathrm{n}=51)\end{array}$ & $\begin{array}{l}\text { Middle-old } \\
(\mathrm{n}=153)\end{array}$ & $\begin{array}{l}\text { Young-old } \\
(\mathrm{n}=346)\end{array}$ & $p$-Value \\
\hline Age, $y r$, mean \pm SD & $87.56 \pm 2.25$ & $81.94 \pm 1.26$ & $77.14 \pm 1.42$ & $<0.001$ \\
\hline Female, n (\%) & $20(39.2)$ & $45(29.4)$ & $92(26.6)$ & 0.167 \\
\hline $\mathrm{BMI}, \mathrm{kg} / \mathrm{m}^{2}$ & $22.96 \pm 2.98$ & $22.79 \pm 2.99$ & $23.04 \pm 3.21$ & 0.763 \\
\hline \multicolumn{5}{|l|}{ Etiology, n (\%) } \\
\hline Alcohol & $7(13.7)$ & $32(20.9)$ & $118(34.1)$ & 0.001 \\
\hline $\mathrm{HBV}$ & $2(3.9)$ & $23(15.0)$ & $67(19.4)$ & 0.020 \\
\hline $\mathrm{HCV}$ & $19(37.3)$ & $46(30.1)$ & $89(25.7)$ & 0.378 \\
\hline Others & $23(45.1)$ & $55(35.9)$ & $88(25.4)$ & 0.003 \\
\hline $\mathrm{DM}(+)$ & $8(34.8)$ & $18(32.7)$ & $45(51.1)$ & 0.072 \\
\hline Resolved HBV infection & $10(43.5)$ & $26(47.3)$ & $50(56.8)$ & 0.613 \\
\hline Obesity* & $8(15.7)$ & $27(17.6)$ & $76(22.0)$ & 0.026 \\
\hline Comorbidity, n (\%) & $38(74.5)$ & $117(76.5)$ & $259(74.9)$ & 0.930 \\
\hline CVD & $11(21.6)$ & $23(15.0)$ & $44(12.7)$ & 0.225 \\
\hline Hypertension & $31(60.8)$ & $88(57.5)$ & $168(48.6)$ & 0.079 \\
\hline Pulmonary disease & $7(13.7)$ & $12(7.8)$ & $11(3.2)$ & 0.003 \\
\hline Diabetes & $14(27.5)$ & $44(28.8)$ & $131(37.9)$ & 0.079 \\
\hline CKD & $3(5.9)$ & $8(5.2)$ & $18(5.2)$ & 0.979 \\
\hline Other cancer & $3(5.9)$ & $15(9.8)$ & $45(13.0)$ & 0.247 \\
\hline Cirrhosis, n (\%) & $35(68.6)$ & $120(78.4)$ & $278(80.3)$ & 0.161 \\
\hline CTP score & $5.92 \pm 1.15$ & $5.82 \pm 1.13$ & $5.99 \pm 1.41$ & 0.422 \\
\hline MELD score & $9.70 \pm 4.47$ & $9.09 \pm 3.96$ & $10.22 \pm 5.91$ & 0.215 \\
\hline FIB-4 test & $6.45 \pm 4.88$ & $6.54 \pm 5.74$ & $6.60 \pm 5.86$ & 0.982 \\
\hline AFP, IU/ml & $2,675 \pm 8,370$ & $3,402 \pm 9,133$ & $3,046 \pm 10,052$ & 0.879 \\
\hline PIVKA-II, mAU/ml & $9,446 \pm 22,595$ & $4,654 \pm 16,240$ & $3,766 \pm 14,990$ & 0.213 \\
\hline Tumor size, $\mathrm{cm}$ & $6.21 \pm 3.76$ & $5.81 \pm 4.02$ & $5.22 \pm 3.90$ & 0.113 \\
\hline Pauci- nodular, n (\%) & $20(39.2)$ & $43(28.1)$ & $91(26.3)$ & 0.162 \\
\hline PVTT, n (\%) & $7(13.7)$ & $24(15.7)$ & $46(13.3)$ & 0.776 \\
\hline Ruptured HCC, n (\%) & $3(5.9)$ & $11(7.2)$ & $21(6.1)$ & 0.876 \\
\hline \multicolumn{5}{|l|}{ mUICC, $\%$} \\
\hline I/II/III/IV-A/IV-B & $2.0 / 43.1 / 21.6 / 17.6 / 15.7$ & $12.4 / 38.6 / 30.1 / 7.8 / 11.1$ & $15.4 / 41.0 / 26.3 / 7.8 / 9.5$ & 0.075 \\
\hline \multicolumn{5}{|l|}{ BCLC, $\%$} \\
\hline $0 / \mathrm{A} / \mathrm{B} / \mathrm{C} / \mathrm{D}$ & $2.0 / 9.8 / 13.7 / 54.9 / 15.7$ & $7.2 / 11.8 / 23.5 / 46.4 / 7.8$ & $6.6 / 17.1 / 21.1 / 45.1 / 8.7$ & 0.231 \\
\hline N/A & 3.9 & 3.3 & 1.4 & \\
\hline \multicolumn{5}{|l|}{ PS, n \% } \\
\hline $0 / 1 / 2 / 3 / 4$ & $33.3 / 45.1 / 5.9 / 13.7 / 2.0$ & $51.6 / 34.6 / 7.2 / 3.9 / 2.6$ & $54.6 / 33.2 / 6.4 / 5.2 / 0.6$ & 0.032 \\
\hline $\begin{array}{l}\text { Active treatment, } \\
\mathrm{n}(\%)\end{array}$ & $18(35.3)$ & $82(53.6)$ & $226(65.3)$ & $<0.001$ \\
\hline
\end{tabular}

BMI: Body mass index; HBV: hepatitis B virus; HCV: hepatitis C virus; DM: diabetes mellitus, Anti-HBc: antibody to hepatitis B core antigen; CVD: cardiovascular disease; CKD: chronic kidney disease; CTP: Child-Turcotte-Pugh; MELD: Model for End Stage Liver Disease; FIB-4: fibrosis4; AFP: alpha fetoprotein; PIVKA-II: protein induced by vitamin K absence-II; mUICC: modified Union for International Cancer Control; BLCLC: Barcelona Clinic Liver Cancer; PVT: portal vein tumor thrombosis; PS: performance status. *A BMI higher than $>25 \mathrm{Kg} / \mathrm{m}^{2}$ is defined as Obese. Isome overlap.

BCLC stages $\mathrm{B}$ and $\mathrm{C}$, but there was no significant difference in BCLC stage A in the extreme elderly group and BCLC stage $\mathrm{D}$ in the non-extreme elderly group (Table V).

Factors related to survival. In the univariate Cox regression analysis, the variables associated with survival were age, BMI, the CTP score, MELD score, PIVKA-II level, tumor size, number of tumors, the presence of PVTT, rupture of HCC, modified UICC stage, BCLC stage, performance score, and active treatment. In the multivariate analysis, age
( $\geq 85$ years), the MELD score, presence of PVTT, rupture of HCC, modified UICC stage, BCLC stage, performance score, and active treatment were significantly associated with OS in all groups (Table VI).

\section{Discussion}

In the present study, clinical characteristics and outcomes of extreme elderly patients with HCC were comprehensively assessed. The strength of our study was that it evaluated 
Table II. Treatment modalities of enrolled patients according to age group.

\begin{tabular}{lccrc}
\hline Variable & $\begin{array}{c}\text { Oldest-old } \\
(\mathrm{n}=51)\end{array}$ & $\begin{array}{c}\text { Middle-old } \\
(\mathrm{n}=153)\end{array}$ & $\begin{array}{c}\text { Young-old } \\
(\mathrm{n}=346)\end{array}$ \\
\hline SR, n (\%) & $0(0.0)$ & $5(3.3)$ & $18(5.2)$ & 0.166 \\
RFA, n (\%) & $1(2.0)$ & $13(8.5)$ & $38(11.0)$ & 0.113 \\
TACE, n (\%) & $11(21.6)$ & $53(34.6)$ & $144(41.6)$ & 0.014 \\
Combination of TACE and RFA, n (\%) & $3(5.9)$ & $3(2.0)$ & $12(3.5)$ & 0.412 \\
Sorafenib, n (\%) & $2(3.9)$ & $6(3.9)$ & $4(1.2)$ & 0.815 \\
RT, n (\%) & $1(2.0)$ & $2(1.3)$ & $101(29.2)$ & 0.719 \\
BSC, n (\%) & $32(62.7)$ & $62(40.5)$ & $<0.001$ \\
\hline
\end{tabular}

SR: Surgical resection; RFA: radiofrequency ablation; TACE: transarterial chemoembolization; BSC: best supportive care.

Table III. Characteristics of patients were underwent active treatment according to age groups.

\begin{tabular}{|c|c|c|c|c|}
\hline Variable & $\begin{array}{l}\text { Oldest-old } \\
\quad(n=18)\end{array}$ & $\begin{array}{l}\text { Middle-old } \\
\quad(\mathrm{n}=82)\end{array}$ & $\begin{array}{l}\text { Young-old } \\
(\mathrm{n}=226)\end{array}$ & $p$-Value \\
\hline \multicolumn{5}{|l|}{ CTP class, $\%$} \\
\hline $\mathrm{A} / \mathrm{B} / \mathrm{C}$ & $88.9 / 11.1 / 0.0$ & $84.1 / 15.9 / 0.0$ & $83.6 / 15.0 / 1.3$ & 0.912 \\
\hline MELD score & $6.00 \pm 3.31$ & $5.76 \pm 3.00$ & $5.71 \pm 3.11$ & 0.929 \\
\hline \multicolumn{5}{|l|}{ mUICC, $\%$} \\
\hline I/II/III/IV-A/IV-B & $5.6 / 55.6 / 22.2 / 11.1 / 5.6$ & $17.1 / 45.1 / 25.6 / 6.1 / 6.1$ & $18.6 / 46.9 / 25.2 / 4.4 / 4.9$ & 0.804 \\
\hline \multicolumn{5}{|l|}{ BCLC, \% } \\
\hline $0 / \mathrm{A} / \mathrm{B} / \mathrm{C} / \mathrm{D}$ & $5.6 / 22.2 / 22.2 / 50.0 / 0.0$ & $9.8 / 18.3 / 28.0 / 43.9 / 0.0$ & $9.3 / 22.6 / 24.3 / 41.2 / 2.7$ & 0.912 \\
\hline Adverse event, $\mathrm{n}(\%)$ & $7(38.9)$ & $34(41.5)$ & $82(36.3)$ & 0.731 \\
\hline 2ndtreatment, n (\%) & $1(5.6)$ & $15(18.3)$ & $38(16.8)$ & 0.431 \\
\hline Number of treatments, mean (range) & $1.56(1-4)$ & $2.27(1-16)$ & $2.69(1-16)$ & $<0.001$ \\
\hline DFS, day & $329.28 \pm 309.05$ & $271.66 \pm 414.15$ & $357.24 \pm 511.55$ & 0.385 \\
\hline \multicolumn{5}{|l|}{ Morbidity, n (\%) } \\
\hline Hospital stay, day & $6.20 \pm 4.69$ & $8.72 \pm 8.16$ & $7.84 \pm 6.72$ & 0.394 \\
\hline Need for ICU, n (\%) & $0(0.0)$ & $3(3.7)$ & $8(3.5)$ & 0.264 \\
\hline Infection, $\mathrm{n}(\%)$ & $0(0.0)$ & $2(2.5)$ & $4(1.8)$ & 0.783 \\
\hline Mortality, n (\%) & $0(0.0)$ & $1(1.2)$ & $0(0.0)$ & 0.250 \\
\hline OS, month, mean \pm SD & $38.45 \pm 8.29$ & $41.54 \pm 4.39$ & $45.84 \pm 2.62$ & 0.430 \\
\hline
\end{tabular}

CTP: Child-Turcotte-Pugh; MELD: Model for End Stage Liver Disease; mUICC: modified Union for International Cancer Control; BCLC: Barcelona Clinic Liver Cancer; DFS: disease free survival; ICU: intensive care unit.

long-term follow-up data regarding patients' cause of death or overall survival for a large number of cases. Our study findings suggest that when using the therapeutic approach in elderly patients with HCC, the patient's performance status, liver function, and stage of cancer should be considered, and its use should not be restricted to those of advanced age. In contrast, conservative treatment should be considered in patients with advanced HCC (mUICC stage IV), those aged $\geq 85$ years, and patients with poor liver function.

In previous studies, elderly patients with $\mathrm{HCC}$ were more likely to be women $(9,23)$, and infected by HCV rather than HBV (24). However, extreme elderly patients with HCC in our study had a significantly lower rate of HBV infection and alcohol-related etiology, whereas the percentage of $\mathrm{HCV}$ and women showed a linear correlation without statistical significance. These findings might be explained by the following: 1) Our cohort had one of the highest seroprevalences of $\mathrm{HCV}$, and affected patients were of advanced aged and had advanced severity of liver disease; thus, many individuals could not reach their expected life span because they had liver-related diseases, including but not limited to variceal bleeding, ascites or $\operatorname{HCC}(25) .2$ ) Additionally, only patients with HCC aged more than 75 years were evaluated so the age difference was only 5 years between the groups.

In addition, our study showed that another etiology of HCC was the most common in the 80 years or older group. The subgroup analysis of other etiology of HCC showed no 
Table IV. Adverse events related to treatment.

\begin{tabular}{|c|c|c|c|c|}
\hline Variable & $\begin{array}{l}\text { Oldest-old } \\
\quad(n=18)\end{array}$ & $\begin{array}{l}\text { Middle-old } \\
\quad(\mathrm{n}=82)\end{array}$ & $\begin{array}{l}\text { Young-old } \\
(\mathrm{n}=226)\end{array}$ & $p$-Value \\
\hline Adverse event, n (\%) & $7(38.9)$ & $34(41.5)$ & $82(36.3)$ & 0.731 \\
\hline Post TACE syndrome, n (\%) & $4(22.2)$ & $13(15.9)$ & $43(19.0)$ & 0.773 \\
\hline Hepatic decompensation, n (\%) & $1(5.6)$ & $13(15.9)$ & $27(11.9)$ & 0.469 \\
\hline Liver abscess, $\mathrm{n}(\%)$ & $0(0.0)$ & $3(3.7)$ & $3(1.3)$ & 0.428 \\
\hline Hand foot syndrome, n (\%) & $1(5.6)$ & $1(1.2)$ & $2(0.9)$ & 0.251 \\
\hline Severe diarrhea, n (\%) & $0(0.0)$ & $0(0.0)$ & $1(0.4)$ & 1.000 \\
\hline CDAD, n $(\%)$ & $1(5.6)$ & $0(0.0)$ & $0(0.0)$ & 0.055 \\
\hline Acute kidney injury, n (\%) & $0(0.0)$ & $0(0.0)$ & $2(0.9)$ & 1.000 \\
\hline Others, n (\%) & $0(0.0)$ & $3(3.7)$ & $4(1.9)$ & 0.590 \\
\hline
\end{tabular}

TACE: Transarterial chemoembolization; CDAD: clostridium difficile-associated disease.

Table V. Overall survival between active treatment group and conservative group according to the HCC staging.

\begin{tabular}{|c|c|c|c|c|c|c|}
\hline & \multicolumn{2}{|c|}{$\begin{array}{c}\text { Extreme elderly } \\
(\mathrm{n}=51) \\
\text { OS, months, mean } \pm \mathrm{SD}\end{array}$} & \multirow[t]{2}{*}{$p$-Value } & \multicolumn{2}{|c|}{$\begin{array}{l}\text { Non-extreme elderly } \\
(\mathrm{n}=499) \\
\text { OS, months, mean } \pm \text { SD }\end{array}$} & \multirow[t]{2}{*}{$p$-Value } \\
\hline & $\begin{array}{c}\text { Active } \\
\text { treatment } \\
(\mathrm{n}=18)\end{array}$ & $\begin{array}{l}\text { Conservative } \\
\text { treatment } \\
(n=33)\end{array}$ & & $\begin{array}{c}\text { Active } \\
\text { treatment } \\
(\mathrm{n}=308)\end{array}$ & $\begin{array}{c}\text { Conservative } \\
\text { treatment } \\
(\mathrm{n}=191)\end{array}$ & \\
\hline \multicolumn{7}{|l|}{ mUICC stage } \\
\hline mUICC I & $\dagger$ & $\dagger$ & N/A & $63.5 \pm 4.8$ & $19.0 \pm 5.2$ & $<0.001$ \\
\hline mUICC II & $22.1 \pm 2.9$ & $8.2 \pm 2.1$ & 0.001 & $47.0 \pm 3.1$ & $24.9 \pm 4.7$ & $<0.001$ \\
\hline mUICC III & $41.6 \pm 16.6$ & $11.0 \pm 4.4$ & 0.002 & $35.8 \pm 4.0$ & $12.0 \pm 1.6$ & $<0.001$ \\
\hline mUICC IV-A & $9.5 \pm 3.9$ & $3.6 \pm 1.2$ & 0.342 & $16.1 \pm 4.3$ & $5.5 \pm 1.3$ & 0.072 \\
\hline mUICC IV-B & $29.0 \pm 0.0$ & $2.0 \pm 1.0$ & 0.090 & $7.6 \pm 1.5$ & $8.0 \pm 2.9$ & 0.209 \\
\hline \multicolumn{7}{|l|}{ BCLC stage } \\
\hline BCLC 0 & $\dagger$ & $\dagger$ & N/A & $68.8 \pm 6.5$ & $18.0 \pm 0.0$ & $<0.001$ \\
\hline BCLC A & $49.0 \pm 14.6$ & $22.0 \pm 0.0$ & 0.351 & $49.3 \pm 3.4$ & $37.5 \pm 12.4$ & 0.045 \\
\hline BCLC B & $26.3 \pm 3.1$ & $9.0 \pm 4.0$ & 0.018 & $43.1 \pm 3.7$ & $11.5 \pm 2.0$ & $<0.001$ \\
\hline BCLC C & $19.1 \pm 4.3$ & $6.1 \pm 1.8$ & $<0.001$ & $35.7 \pm 3.4$ & $14.5 \pm 2.1$ & $<0.001$ \\
\hline BCLC D & $\dagger$ & $4.5 \pm 2.3$ & N/A & $9.1 \pm 2.7$ & $8.4 \pm 2.4$ & 0.174 \\
\hline
\end{tabular}

OS: Overall survival; mUICC: modified Union for International Cancer Control; BCLC: Barcelona Clinic Liver Cancer; N/A: not available. $\dagger$ No statistics are computed because all cases are censored.

statistically significant difference in DM and resolved HBV infection. Moreover, the prevalence of obesity and DM was higher in the oldest-old group than in the middle-old group. This finding is likely associated with the increasing incidence of HCC related to non-alcoholic fatty liver disease (NAFLD) in elderly patients. Obesity and DM have been reported to be risk factors for HCC in large cohort and experimental studies $(26,27)$. The increased risk of HCC being associated with obesity and DM is probably due to the increased prevalence of NAFLD and the potential of the premalignant HCC condition to be related to obesity and DM (28).

In many studies, elderly patients with HCC were more likely to have a pauci-nodular HCC, less advanced fibrosis, and more preserved liver function $(7,29,30)$. However, some studies reported no statistical difference between elderly and younger patients, and the tumor stage was not different in our patient groups (31-33). Conversely, our data did not show a difference in the number of tumors and fibrosis in terms of radiologic imaging or laboratory findings. Collier et al. and Dohmen et al. did not demonstrate any difference in results of liver function tests and the CTP score across age cutoffs of 65 or 70 years (31, 34). Our data also showed no significant difference in hepatic reserve function in terms of the CTP score and MELD score.

In general, elderly patients have a significantly higher percentage of comorbid diseases than younger patients do, and this could have affected patients' outcomes $(7,11,18)$. However, most elderly patients with HCC aged over 80 years died of an HCC-related cause, and there were no significant 


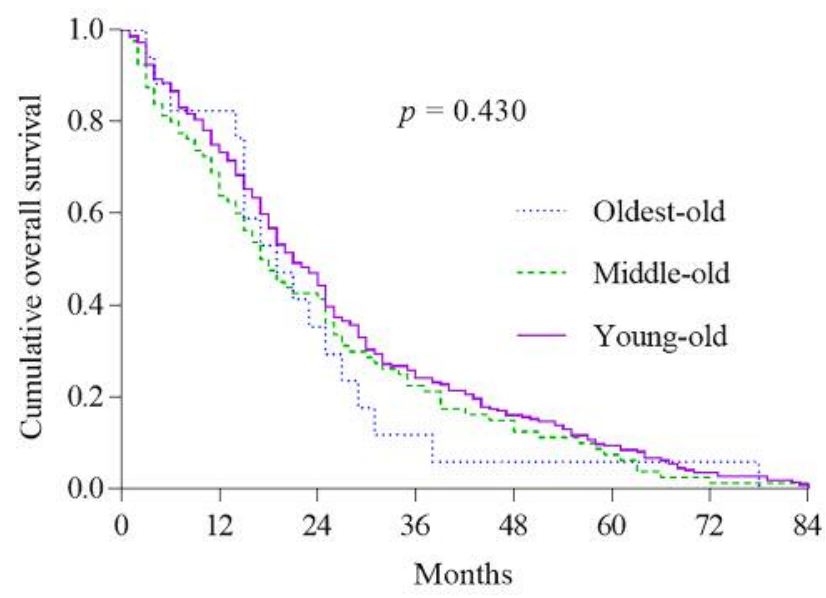

Figure 2. Cumulative overall survival between oldest-old ( $\geq 85$ years), middle-old (between 85 and 80 years) and young-old (between 80 and 75 years) in HCC patient with active treatment. HCC: Hepatocellular carcinoma.

differences in the percentage of liver-related deaths and deaths related to other causes between elderly and younger patients (18). Our study showed that elderly patients with HCC had more comorbidities, which is consistent with the result of a previous study (18). Although the prevalence of liver-related death was not assessed because of our retrospective study design, there was no significant difference in OS according to underlying comorbidities by age.

Regarding the initial treatment in our study, the oldest-old group received exclusively conservative treatment in $62.7 \%$ of the cases compared to only $40.5 \%$ and $29.2 \%$ in the middle-old group and young-old group, respectively. Similar to our study, previous studies reported that elderly patients with HCC were more likely to receive conservative treatment than were younger patients (31-33). Additionally, our patients received fewer curative treatments, such as surgical resection or RFA. These findings indicate that compared to younger patients, elderly patients received fewer aggressive or risky types of treatments, although there were no differences with respect to the prognosis of HCC treated with active treatment.

Consistent with other studies, $(8-12,32)$ no statistical difference was found in treatment-related adverse events and disease-free survival between the active treatment groups by age. Furthermore, there was no significant difference in the duration of hospital stay and need for ICU care. The most common adverse event was post-TACE syndrome, and treatment-related mortality occurred in only 1 case. The other types of complications did not increase with age. Our results suggest that active treatment is efficacious and safe in elderly patients with HCC.
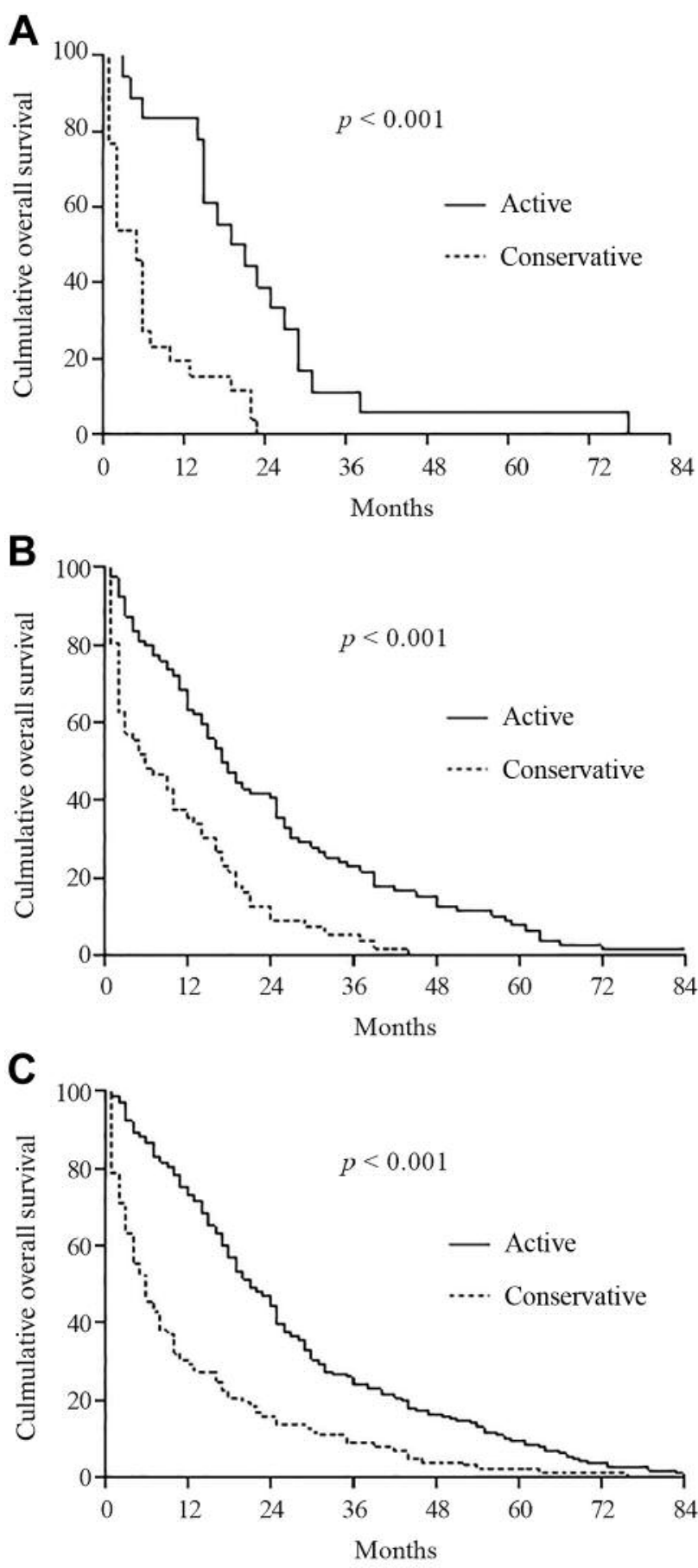

Figure 3. Cumulative overall survival between active treatment and conservative treatment by age groups. A: oldest-old group ( $\geq 85$ years); B: Middle-old group (between 85 and 80 years); C: Young-old group (between 80 and 75 years).

Our results showed a significant difference in OS between the groups, and similar results were obtained in the subgroup analysis of the intermediate stages of cancer. This finding 
Table VI. Univariate and multivariate analysis for mortality in all HCC patients.

\begin{tabular}{|c|c|c|c|c|c|}
\hline \multirow[t]{2}{*}{ Variable } & \multicolumn{2}{|c|}{ Univariate } & \multicolumn{3}{|c|}{ Multivariate } \\
\hline & $\begin{array}{l}\text { Unadjusted } \\
\text { hazard ratio }\end{array}$ & $p$-Value & $\begin{array}{c}\text { Adjusted } \\
\text { hazard ratio }\end{array}$ & $95 \% \mathrm{CI}$ & $p$-Value \\
\hline \multicolumn{6}{|l|}{ Age } \\
\hline Middle-/Young-old & 1.452 & 0.001 & & & \\
\hline Oldest-/Young-old & & & 1.630 & $1.096-2.423$ & 0.016 \\
\hline Gender (female/male) & 0.909 & 0.452 & & & \\
\hline BMI $(>25 / \leq 25)$ & 1.366 & $<0.001$ & & & \\
\hline \multicolumn{6}{|l|}{ Etiology } \\
\hline Alcohol & 0.971 & 0.820 & & & \\
\hline $\mathrm{HBV}$ & 1.155 & 0.337 & & & \\
\hline $\mathrm{HCV}$ & 1.052 & 0.689 & & & \\
\hline ETC & 1.220 & 0.100 & & & \\
\hline Comorbidity & 0.811 & 0.094 & & & \\
\hline Cardiovascular & 1.001 & 0.996 & & & \\
\hline Hypertension & 0.951 & 0.658 & & & \\
\hline Pulmonary disease & 1.159 & 0.545 & & & \\
\hline Diabetes & 1.101 & 0.418 & & & \\
\hline Chronic renal disease & 1.142 & 0.556 & & & \\
\hline Cirrhosis & 1.039 & 0.782 & & & \\
\hline CTP (B,C/A) & 2.361 & $<0.001$ & & & \\
\hline $\operatorname{MELD}(\geq 10 /<10)$ & 1.955 & $<0.001$ & 1.676 & $1.307-2.149$ & $<0.001$ \\
\hline $\operatorname{AFP}(>200 / \leq 200)$ & 1.232 & 0.082 & & & \\
\hline PIVKA-II $(>40 / \leq 40)$ & 1.527 & 0.019 & & & \\
\hline Tumor size $(>2 / \leq 2)$ & 2.303 & $<0.001$ & & & \\
\hline Paucinodular & 2.483 & $<0.001$ & & & \\
\hline PVTT & 4.153 & $<0.001$ & 2.561 & $1.857-3.533$ & $<0.001$ \\
\hline HCC rupture & 2.599 & $<0.001$ & 2.935 & $1.975-4.632$ & $<0.001$ \\
\hline \multicolumn{6}{|l|}{ mUICC } \\
\hline (III, IV-A, IV-B/I,II) & 2.688 & $<0.001$ & 1.499 & $1.091-2.060$ & 0.013 \\
\hline $\mathrm{BCLC}(\mathrm{B}, \mathrm{C}, \mathrm{D} / 0, \mathrm{~A})$ & 3.145 & $<0.001$ & 1.566 & $1.079-2.272$ & 0.018 \\
\hline PS $(2,3,4 / 0,1)$ & 3.159 & $<0.001$ & 1.463 & $1.047-2.047$ & 0.026 \\
\hline Active treatment & 0.252 & $<0.001$ & 0.402 & $0.308-0.526$ & $<0.001$ \\
\hline
\end{tabular}

BMI: Body mass index; HBV: hepatitis B virus; HCV: hepatitis C virus; CTP: Child-Turcotte-Pugh; MELD: Model for End Stage Liver Disease; AFP: alpha fetoprotein; PIVKA-II: protein induced by vitamin K absence-II; mUICC: modified Union for International Cancer Control; BLCLC: Barcelona Clinic Liver Cancer; PVT: portal vein tumor thrombosis; PS: performance status.

was consistent with findings of other recent reports $(8,13$, $17)$, but they mostly studied patients aged 70 years or older $(7,10,11,18,19)$. Hori et al. reported that OS was shorter for elderly patients (aged 75 years or older) than for younger patients. However, the OS of the elderly group, after excluding patients with supportive care alone, was similar to that of the younger group (17). Therefore, active treatment should be considered in patients with intermediate-stage HCC who have preserved liver function.

In addition, the subgroup analysis of OS showed no statistical difference between the active-treatment group and conservative group, as stratified by BCLC stage A in the oldest-old group. We presumed that these patients who did not receive curative treatments because of their age or the presence of comorbidities despite having an early stage of
HCC are more likely to die of cirrhotic complications or diseases other than progression of liver cancer.

Our multivariate analysis identified age ( $\geq 85$ years), the MELD score, mUICC stage, BCLC stage, presence of PVTT, rupture of $\mathrm{HCC}$, performance score, and active treatment as significant independent prognostic factors of OS. In contrast to a previous report $(29,30,33-37)$, advanced age was one of the factors contributing to poor prognosis in patients with HCC, but this was similar to the finding of one recent report (13). Suda et al. highlighted that aging was not a poor prognostic factor affecting OS of patients with HCC when the survival benefit was evaluated based on the percent survival to life expectancy (a ratio of the survival days to the expected residual life length). Therefore, the therapeutic approach should not be restricted because of patient's age (13). 
This study had several limitations. First, it was a retrospective, single-center study. Thus, the possibility of unintended selection bias could not be excluded. Second, we only analyzed the initial treatment outcomes, although many patients were treated with various and multiple treatment modalities during the follow-up period. Therefore, it was difficult to evaluate the effects of all the therapies on prognosis in this cohort. More prospective studies are needed to confirm our findings.

In conclusion, our data support that the treatment strategy of HCC does not differ between elderly patients including extreme elderly patients and younger patients. Hence, clinicians should determine the optimal treatment strategies based on the patients' performance status, hepatic reserve capacity, and tumor stage, regardless of their age and comorbidities.

\section{Conflicts of Interest}

There are no conflicts of interest regarding this study.

\section{Acknowledgements}

This work was supported by Grants (CRI 1809-1 and CRI 170271) from the Chonnam National University Hospital Biomedical Research Institute.

\section{References}

1 Jemal A, Bray F, Center MM, Ferlay J, Ward E and Forman D: Global cancer statistics. CA Cancer J Clin 61(2): 69-90, 2011.

2 Bosch FX, Ribes J, Diaz M and Cleries R: Primary liver cancer: Worldwide incidence and trends. Gastroenterology 127(5 Suppl 1): S5-s16, 2004.

3 Cho SJ, Yoon JH, Hwang SS and Lee HS: Do young hepatocellular carcinoma patients with relatively good liver function have poorer outcomes than elderly patients? J Gastroenterol Hepatol 22(8): 1226-1231, 2007.

4 Asahina Y, Tsuchiya K, Tamaki N, Hirayama I, Tanaka T, Sato M, Yasui Y, Hosokawa T, Ueda K, Kuzuya T, Nakanishi H, Itakura J, Takahashi Y, Kurosaki M, Enomoto N and Izumi N: Effect of aging on risk for hepatocellular carcinoma in chronic hepatitis c virus infection. Hepatology 52(2): 518-527, 2010.

5 Borzio M, Dionigi E, Parisi G, Raguzzi I and Sacco R: Management of hepatocellular carcinoma in the elderly. World J Hepatol 7(11): 1521-1529, 2015.

6 Kowal P and Edward Dowd J: Definition of an older person. Proposed working definition of an older person in africa for the mds project. 2001.

7 Mirici-Cappa F, Gramenzi A, Santi V, Zambruni A, Di Micoli A, Frigerio M, Maraldi F, Di Nolfo MA, Del Poggio P, Benvegnu L, Rapaccini G, Farinati F, Zoli M, Borzio F, Giannini EG, Caturelli E, Bernardi $M$ and Trevisani F: Treatments for hepatocellular carcinoma in elderly patients are as effective as in younger patients: A 20-year multicentre experience. Gut 59(3): 387-396, 2010.

8 Liu PH, Hsu CY, Lee YH, Hsia CY, Huang YH, Su CW, Chiou YY, Lin HC and Huo TI: Uncompromised treatment efficacy in elderly patients with hepatocellular carcinoma: A propensity score analysis. Medicine (Baltimore) 93(28): e264, 2014.

9 Oishi K, Itamoto T, Kohashi T, Matsugu Y, Nakahara H and Kitamoto M: Safety of hepatectomy for elderly patients with hepatocellular carcinoma. World J Gastroenterol 20(41): 1502815036, 2014.

10 Nishikawa H, Kita R, Kimura T, Ohara Y, Takeda H, Sakamoto A, Saito S, Nishijima N, Nasu A, Komekado H and Osaki Y: Transcatheter arterial chemoembolization for intermediate-stage hepatocellular carcinoma: Clinical outcome and safety in elderly patients. J Cancer 5(7): 590-597, 2014.

11 Cohen MJ, Bloom AI, Barak O, Klimov A, Nesher T, Shouval D, Levi I and Shibolet O: Trans-arterial chemo-embolization is safe and effective for very elderly patients with hepatocellular carcinoma. World J Gastroenterol 19(16): 2521-2528, 2013.

12 Yau T, Yao TJ, Chan P, Epstein RJ, Ng KK, Chok SH, Cheung TT, Fan ST and Poon RT: The outcomes of elderly patients with hepatocellular carcinoma treated with transarterial chemoembolization. Cancer 115(23): 5507-5515, 2009.

13 Suda T, Nagashima A, Takahashi S, Kanefuji T, Kamimura K, Tamura Y, Takamura M, Igarashi M, Kawai H, Yamagiwa S, Nomoto $\mathrm{M}$ and Aoyagi $\mathrm{Y}$ : Active treatments are a rational approach for hepatocellular carcinoma in elderly patients. World J Gastroenterol 19(24): 3831-3840, 2013.

14 Korean statistical information service [internet]. Available at http://kostatgokr/portal/korea/kor_nw/3/indexboard?bmode=read $\& b S e q=\& a S e q=357775 \&$ page $\mathrm{No}=1 \&$ row Num $=10 \&$ navCount $=1$ $0 \&$ currPg $=\&$ sTarget $=$ title $\&$ sT $x t=[$ accessed on 25 December 2017], 2016.

15 Bugianesi E: Non-alcoholic steatohepatitis and cancer. Clin Liver Dis 11(1): 191-207, x-xi, 2007.

16 Camma C, Giunta M, Andreone P and Craxi A: Interferon and prevention of hepatocellular carcinoma in viral cirrhosis: An evidence-based approach. J Hepatol 34(4): 593-602, 2001.

17 Hori M, Tanaka M, Ando E, Sakata M, Shimose S, Ohno M, Yutani S, Kuraoka K, Kuromatsu R, Sumie S and Sata M: Longterm outcome of elderly patients (75 years or older) with hepatocellular carcinoma. Hepatol Res 44(9): 975-982, 2014.

18 Kinoshita A, Onoda H, Ueda K, Imai N, Iwaku A, Tanaka K, Fushiya N, Koike K, Nishino $\mathrm{H}$ and Tajiri $\mathrm{H}$ : Clinical characteristics and survival outcomes of super-elderly hepatocellular carcinoma patients not indicated for surgical resection. Hepatol Res 46(3): E5-e14, 2016.

19 Kim YJ, Jang BK, Kim ES, Chung WJ, Park KS, Cho KB and Hwang JS: Hepatocellular carcinoma in the elderly: Clinical characteristics, treatment, survival analysis in korean patients older than 70 years. J Korean Med Sci 27(10): 1147-1154, 2012.

20 Bellera CA, Rainfray M, Mathoulin-Pelissier S, Mertens C, Delva F, Fonck M and Soubeyran PL: Screening older cancer patients: First evaluation of the g- 8 geriatric screening tool. Ann Oncol 23(8): 2166-2172, 2012.

21 Zizza CA, Ellison KJ and Wernette CM: Total water intakes of community-living middle-old and oldest-old adults. J Gerontol A Biol Sci Med Sci 64(4): 481-486, 2009.

222014 korean liver cancer study group-national cancer center korea practice guideline for the management of hepatocellular carcinoma. Korean J Radiol 16(3): 465-522, 2015.

23 El-Serag HB and Mason AC: Rising incidence of hepatocellular carcinoma in the united states. N Engl J Med 340(10): 745-750, 1999. 
24 El-Serag HB: Epidemiology of viral hepatitis and hepatocellular carcinoma. Gastroenterology 142(6): 1264-1273.e1261, 2012.

25 Shon HS, Choi HY, Kim JR, Ryu SY, Lee YJ, Lee MJ, Min HJ, Lee J, Song YJ and Ki M: Comparison and analysis of the prevalence of hepatitis $\mathrm{c}$ virus infection by region in the republic of korea during 2005-2012. Clin Mol Hepatol 21(3): 249-256, 2015.

26 El-Serag HB, Tran T and Everhart JE: Diabetes increases the risk of chronic liver disease and hepatocellular carcinoma. Gastroenterology 126(2): 460-468, 2004.

27 Calle EE, Rodriguez C, Walker-Thurmond K and Thun MJ: Overweight, obesity, and mortality from cancer in a prospectively studied cohort of u.S. Adults. N Engl J Med 348(17): 1625-1638, 2003.

28 Tokushige K, Hashimoto E, Horie Y, Taniai M and Higuchi S: Hepatocellular carcinoma based on cryptogenic liver disease: The most common non-viral hepatocellular carcinoma in patients aged over 80 years. Hepatol Res 45(4): 441-447, 2015.

29 Nishikawa H, Arimoto A, Wakasa T, Kita R, Kimura T and Osaki Y: Surgical resection for hepatocellular carcinoma: Clinical outcomes and safety in elderly patients. Eur J Gastroenterol Hepatol 25(8): 912-919, 2013.

30 Huang J, Li BK, Chen GH, Li JQ, Zhang YQ, Li GH and Yuan YF: Long-term outcomes and prognostic factors of elderly patients with hepatocellular carcinoma undergoing hepatectomy. J Gastrointest Surg 13(9): 1627-1635, 2009.

31 Collier JD, Curless R, Bassendine MF and James OF: Clinical features and prognosis of hepatocellular carcinoma in britain in relation to age. Age Ageing 23(1): 22-27, 1994.

32 Poon RT, Fan ST, Lo CM, Liu CL, Ngan H, Ng IO and Wong J: Hepatocellular carcinoma in the elderly: Results of surgical and nonsurgical management. Am J Gastroenterol 94(9): 2460-2466, 1999.
33 Tsukioka G, Kakizaki S, Sohara N, Sato K, Takagi H, Arai H, Abe T, Toyoda M, Katakai K, Kojima A, Yamazaki Y, Otsuka T, Matsuzaki Y, Makita F, Kanda D, Horiuchi K, Hamada T, Kaneko M, Suzuki H and Mori M: Hepatocellular carcinoma in extremely elderly patients: An analysis of clinical characteristics, prognosis and patient survival. World J Gastroenterol 12(1): 4853, 2006.

34 Dohmen K, Shirahama M, Shigematsu H, Irie K and Ishibashi H: Optimal treatment strategy for elderly patients with hepatocellular carcinoma. J Gastroenterol Hepatol 19(8): 859-865, 2004.

35 Ferrero A, Vigano L, Polastri R, Ribero D, Lo Tesoriere R, Muratore A and Capussotti L: Hepatectomy as treatment of choice for hepatocellular carcinoma in elderly cirrhotic patients. World J Surg 29(9): 1101-1105, 2005.

36 Hiraoka A, Michitaka K, Horiike N, Hidaka S, Uehara T, Ichikawa S, Hasebe A, Miyamoto Y, Ninomiya T, Sogabe I, Ishimaru Y, Kawasaki H, Koizumi Y, Hirooka M, Yamashita Y, Abe M, Hiasa Y, Matsuura B and Onji M: Radiofrequency ablation therapy for hepatocellular carcinoma in elderly patients. J Gastroenterol Hepatol 25(2): 403-407, 2010.

37 Tateishi R, Shiina S, Teratani T, Obi S, Sato S, Koike Y, Fujishima T, Yoshida H, Kawabe T and Omata M: Percutaneous radiofrequency ablation for hepatocellular carcinoma. An analysis of 1000 cases. Cancer 103(6): 1201-1209, 2005.

Received September 20, 2018

Revised October 8, 2018

Accepted October 9, 2018 